\title{
Attitudes toward evidence-based clinical practice among doctors of chiropractic with diplomate- level training in orthopedics
}

\author{
Christopher B Roecker ${ }^{1 *}$, Cynthia R Long², Robert D Vining ${ }^{2}$ and Dana J Lawrence ${ }^{1}$
}

\begin{abstract}
Background: Evidence-based clinical practice (EBCP) is a practice model gaining prominence within healthcare, including the chiropractic profession. The status of EBCP has been evaluated in a variety of healthcare disciplines, but little is known regarding the attitudes doctors of chiropractic (DCs) hold toward this model of healthcare. This project examines the attitudes toward EBCP within a specialty discipline of DCs.

Methods: We identified a survey questionnaire previously used to evaluate EBCP among non-chiropractic complementary and alternative practitioners. We adapted this questionnaire for use among DCs and pretested it in 5 chiropractic college faculty. The final version was administered to DCs with diplomate-level training in orthopedics. The survey was emailed to 299 potential participants; descriptive results were calculated.

Results: 144 surveys were returned, resulting in a $48 \%$ response rate. The majority of respondents perceived EBCP as an important aspect of chiropractic practice. Respondents also believed themselves to have an above average skill level in EBCP, reported that training originated from their diplomate education, and based the majority of their practice on clinical research.

Conclusion: Doctors of chiropractic with an orthopedic diplomate appear to have favorable attitudes toward EBCP. Further study will help understand EBCP perceptions among general field DCs. A logical next step includes validation of this questionnaire.
\end{abstract}

Keywords: Evidence based practice, Cross-sectional study, Chiropractic, Survey

\section{Background}

Evidence-based clinical practice (EBCP) is "the conscientious, explicit and judicious use of the best evidence when making decisions about the care of individual patients" [1]. This approach assists clinicians with clinical decision-making by integrating clinical expertise, patient values, and the best research evidence in an attempt to optimize clinical outcomes [1,2]. EBCP is a tool clinicians use to promote high-quality and consistent clinical care, justify clinical decision-making, and facilitate interdisciplinary cooperation [3-5]. This approach to clinical practice began formally in the early 1990s, has attracted widespread attention as an important method for improving patient outcomes, [6-8] and has become a

\footnotetext{
* Correspondence: christopher.roecker@palmer.edu

'Palmer College of Chiropractic, 1000 Brady Street, Davenport, IA 52803, USA Full list of author information is available at the end of the article

of the article
}

foundational principle among healthcare professionals [9-15]. This transition to EBCP represents a dramatic advance within healthcare, which attempts to deemphasize unsystematic clinical rationale and intuition in order to enhance clinical outcomes $[6,16]$.

Efforts to promote EBCP within chiropractic have been identified as a fundamental component for advancing the profession [17-19]. Historically, doctors of chiropractic (DCs) have relied heavily on uncritical rationalism (deduction from theory) and uncritical empiricism (casual observation) as justification for chiropractic clinical practice $[20,21]$. More recently, however, the chiropractic profession is embracing the transition to EBCP, [22-24] though obstacles remain that can hinder acceptance of this mode of practice [25].

Even though adoption of EBCP by the chiropractic profession has been promoted by administrators and

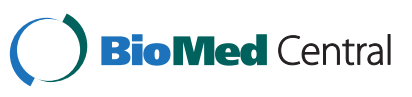


academics, [17] little is known regarding the attitudes practicing DCs hold toward EBCP. Assessments of EBCP have been conducted in many healthcare subspecialties, [26-34] but not within chiropractic. Investigating EBCP among practicing DCs is necessary to understand how EBCP is perceived and practiced, and to inform future research and educational opportunities.

Understanding the attitudes DCs have toward EBCP is an important waypoint for integrating EBCP into clinical practice. As a preliminary step, we surveyed EBCP perceptions in a specialty discipline of DCs. The objective of this project was to adapt a previously established EBCP questionnaire for use with DCs, pretest the questionnaire, and administer it to a convenience sample of DCs.

\section{Methods}

DCs with postgraduate diplomate-level training in nonsurgical chiropractic orthopedics (known as orthopedic diplomates) with membership in the Academy of Chiropractic Orthopedists (ACO) were surveyed in this study. Chiropractic orthopedic diplomates complete 300 hours of postgraduate education in non-surgical orthopedics and may represent the largest chiropractic group with diplomate-level training [35]. We conducted an anonymous, cross-sectional, online survey of EBCP perceptions held by members of the ACO. The Palmer College of Chiropractic Institutional Review Board approved this project.

\section{Survey questionnaire}

A review of the literature demonstrated that the EvidenceBased Practice Attitudes and Utilization Survey (E-BASE) questionnaire [26] was an appropriate survey to adapt for specific application to DCs. This questionnaire has been validated [36] and successfully used to assess attitudes toward EBCP in a population of non-chiropractic complementary and alternative medicine (CAM) practitioners [26]. Permission to adapt the E-BASE survey for this project was provided by its author (Matthew J. Leach, RN, PhD, personal communication, Apr. 9, 2012).

Because the E-BASE survey was designed for use with a variety of non-chiropractic complementary and alternative medicine (CAM) practitioners, it required adaptation and pretesting prior to administration to a population of DCs. Adapting the E-BASE survey was primarily limited to modifying its terminology and design for use in an online format. The adapted questionnaire, specific to practicing DCs, is termed the Chiropractic Evidence-Based Practice Attitudes and Utilization Survey (Chiropractic EBASE). The adapted questionnaire evaluates the following areas: the level of importance placed on EBCP; the level of skills respondents perceive they have to practice EBCP; the level of prior training to practice EBCP; EBCP practice perceptions; perceived barriers preventing the practice of
EBCP; and perceived factors facilitating use of EBCP. It also collects anonymous demographic information.

\section{Pretesting}

The adapted questionnaire was pretested on 5 chiropractic college faculty members with advanced training in EBCP to investigate content validity, clarity, and usability. After completing the online survey, the pretesters were interviewed and narrative feedback was collected.

This feedback informed us that the questionnaire took between 7 and 15 minutes to complete. Recommendations were limited to minor grammatical refinements to maximize clarity and usability within the online format. No suggestions were made to address content validity. All suggestions were incorporated into the Chiropractic E-BASE questionnaire.

\section{Eligibility criteria}

This survey was performed with a convenience sample of DCs with active membership in the ACO who had provided an email contact to the ACO. Informed consent was required for participation and an online informed consent document was provided prior to initiating the online survey.

\section{Recruitment}

The ACO Executive Board provided the email addresses to the ACO membership directory as of August 1, 2012. All ACO members with an active email address were invited to participate via email on August 1, 2012 and reminder emails were sent to non-responders at 1, 2, and 3 weeks after the initial invitation. Opt-out instructions were provided with each email contact.

\section{Study design}

The online survey was administered by the online survey hosting site SurveyMonkey ${ }^{\mathrm{Ts}}$ for the duration of 1 month (August 1, 2012 to August 31, 2012). Descriptive survey data were summarized in tables using frequency counts and percentages.

\section{Results}

At the time of the survey, the ACO had 325 members, of which 309 (95\%) had email addresses. Survey invitations were sent to all 309 email addresses, but 10 members had previously opted-out from all SurveyMonkey ${ }^{\text {тM }}$ surveys. Therefore, 299 of the 325 active ACO members (92\%) were available to participate. Of the 148 ACO members who then opened the link to the online survey, 144 agreed to the informed consent and proceeded to the Chiropractic E-BASE survey. The response rate for this project was $48 \%(144 / 299)$.

Demographics of the survey respondents are given in Table 1. The majority of respondents were male, older 
Table 1 Characteristics of the Academy of Chiropractic Orthopedists responding to the chiropractic E-BASE $(n=129)$

\begin{tabular}{|c|c|c|c|}
\hline Variable & Category & Count & Percent (\%) \\
\hline \multicolumn{4}{|c|}{ Age (years) } \\
\hline & $20-29$ & 0 & 0 \\
\hline & $30-39$ & 11 & 9 \\
\hline & $40-49$ & 26 & 20 \\
\hline & $50-59$ & 63 & 49 \\
\hline & $60-69$ & 29 & 23 \\
\hline \multicolumn{4}{|l|}{ Sex } \\
\hline & Male & 117 & 91 \\
\hline \multicolumn{4}{|c|}{$\begin{array}{l}\text { Years since receiving } \\
\text { Doctor of Chiropractic } \\
\text { degree }\end{array}$} \\
\hline & $<1$ & 0 & 0 \\
\hline & $1-5$ & 2 & 2 \\
\hline & $6-10$ & 3 & 2 \\
\hline & $11-15$ & 13 & 10 \\
\hline & $\geq 16$ & 111 & 86 \\
\hline \multicolumn{4}{|c|}{$\begin{array}{l}\text { Years of chiropractic } \\
\text { practice }\end{array}$} \\
\hline & $<1$ & 0 & 0 \\
\hline & $1-5$ & 1 & 1 \\
\hline & $6-10$ & 3 & 2 \\
\hline & $11-15$ & 13 & 10 \\
\hline & $\geq 16$ & 112 & 87 \\
\hline \multicolumn{4}{|c|}{$\begin{array}{l}\text { Predominant } \\
\text { practice setting }\end{array}$} \\
\hline & Solo practice & 75 & 58 \\
\hline & $\begin{array}{l}\text { Group of CAM } \\
\text { practitioners }\end{array}$ & 26 & 20 \\
\hline & $\begin{array}{l}\text { Combination of } \\
\text { CAM and medical } \\
\text { practitioners }\end{array}$ & 10 & 8 \\
\hline & $\begin{array}{l}\text { Institution (e.g. hospital } \\
\text { or medical center) }\end{array}$ & 10 & 8 \\
\hline & Educational institution & 8 & 6 \\
\hline
\end{tabular}

CAM complementary and alternative medicine.

than 40 years of age, and had at least 16 years of practice experience. More than $40 \%$ were located in the Midwest United States and 58\% practiced as a solo practitioner. Survey respondents were also likely to be members of the American Chiropractic Association (76\%).

Between $80-89 \%$ of the respondents agreed or strongly agreed that EBCP is necessary to chiropractic practice, improves the quality of patient care, assists them in making decisions about patient care, find research useful in their day-to-day practice, reported the prioritization of EBCP within chiropractic as a fundamental component for the future advancement of the profession, and are interested in improving their EBCP skills. Only 39\% agreed or strongly agreed that EBCP takes into account a patient's preference for treatment.

The majority of respondents believed they had above average skills when identifying answerable clinical questions and knowledge gaps, locating professional literature, and applying research evidence to patient care (Table 2).

With regard to where training in EBCP originated, $41 \%$ reported that it came from their diplomate education, while $15 \%$ reported it came via personal study, and a small percent $(3 \%)$ noted it came during their chiropractic education. Additionally, 21\% reported that applying research evidence to clinical practice was attributable to their diplomate education.

The majority (53\%) reported that over half of their practice was based on clinical research evidence. Over two-thirds of respondents reported engaging in EBCP activities at least once within the past month, including reviewing clinical research (94\%), online database searching $(73 \%)$, and using professional literature to change clinical practice (88\%) (Table 3). The sources of information used most frequently to inform clinical decision-making were traditional knowledge, published clinical evidence, and clinical practice guidelines (Table 4). The least common were trial and error and patient preference.

More than $80 \%$ of respondents perceived that the barriers to implementing EBCP included a lack of clinical evidence in CAM and a lack of time (Table 5). Issues reported to not act as a barrier to EBCP were lack of resources (65\%), lack of interest in EBCP (55\%), lack of relevance to chiropractic practice (48\%), and lack of colleague support (47\%) (Table 5). Factors reported to be moderately to very useful for facilitating EBCP included access to the internet at work (96\%), free online databases at work (70\%), online EBCP educational material (89\%), critical reviews of research within the chiropractic profession (90\%), and the ability to download full-text articles $(82 \%)$.

\section{Discussion}

To our knowledge this study represents the first survey of practicing DCs directly related to EBCP. We found that participants held favorable attitudes toward EBCP and consider this model to be an important component for the current practice and advancement of the chiropractic profession. The positive perceptions reported in this survey are comparable to the positive self-reported perceptions of other healthcare professionals [26-29,31-34]. Our results suggest that the majority of DCs with diplomate-level training in orthopedics embrace EBCP while serving as the first measure of EBCP perceptions within a subset of practicing DCs.

Respondents reported the majority of their EBCP knowledge originated from the postgraduate orthopedic 
Table 2 The skill level chiropractic orthopedic diplomates have in evidence-based clinical practice (5-point Likert scale) $(n=143)$

\begin{tabular}{|c|c|c|c|c|c|}
\hline & 1 (poor) (\%) & $2(\%)$ & 3 (average) (\%) & $4(\%)$ & 5 (advanced) (\%) \\
\hline Identifying knowledge gaps in practice & $0(0)$ & $4(2.8)$ & $32(22.4)$ & $75(42.4)$ & $65(52.4)$ \\
\hline Identifying answerable clinical questions & $0(0)$ & $1(0.7)$ & $11(7.7)$ & $77(53.8)$ & $54(37.8)$ \\
\hline Locating professional literature & $2(1.4)$ & $8(5.6)$ & $36(25.2)$ & $54(37.8)$ & $43(30.1)$ \\
\hline Online database searching & $5(3.5)$ & $15(10.5)$ & $38(26.6)$ & $43(30.1)$ & $42(29.4)$ \\
\hline Retrieving evidence & $5(3.5)$ & $16(11.2)$ & $43(30.1)$ & $46(32.2)$ & $33(23.1)$ \\
\hline Critical appraisal of the evidence & $7(4.9)$ & 19 (13.3) & $41(28.7)$ & $56(39.2)$ & $20(14.0)$ \\
\hline Applying research evidence to patient care & $4(2.8)$ & $11(7.7)$ & $36(25.2)$ & $70(49.0)$ & $22(15.4)$ \\
\hline Using findings from clinical research & $4(2.8)$ & $16(11.2)$ & $46(32.2)$ & $59(41.3)$ & $18(12.6)$ \\
\hline Using findings from systematic reviews & $14(9.8)$ & $25(17.5)$ & $40(28.0)$ & 48 (33.6) & $16(11.2)$ \\
\hline Synthesis of research evidence & $8(5.6)$ & $18(12.6)$ & $58(40.6)$ & $45(31.5)$ & $14(9.8)$ \\
\hline
\end{tabular}

diplomate training program. While postgraduate training in chiropractic orthopedics may incorporate aspects of EBCP, these competencies are not officially part of the curriculum (ACO Executive Board, personal communication, July 2, 2013). Despite this, it is evident that chiropractic orthopedic diplomates perceive their postgraduate educational program as a source of EBCP training. It is likely this originates from the informal inclusion of EBCP concepts into the training program.

This survey found that the majority of respondents were interested in having access to EBCP educational material. These findings are consistent with the results of other surveys intended to highlight factors facilitating EBCP in other healthcare disciplines $[26,29,34]$. Current continuing chiropractic education opportunities focused on the principles of EBCP are uncommon and may represent an unmet subject area. Also, because the Council on Chiropractic Education has recently established EBCP competency requirements for U.S. chiropractic education, [24] providing postgraduate EBCP educational opportunities for DCs trained prior to the implementation of these educational competencies is important. Future efforts should be directed toward developing focused postgraduate EBCP educational opportunities for DCs.

The information sources used to inform clinical decision-making reported in this survey were nearly identical to those used by other CAM practitioners [26]. These findings prioritized clinical information obtained from traditional knowledge, published clinical evidence, and clinical practice guidelines as the most frequently used source of clinical information. Interestingly, patient preference was rated as one of the least frequently used sources of information. Because the primary objective of $\mathrm{EBCP}$ is to integrate the clinician's clinical expertise, the patient's values, and the best research evidence, [16] these results may indicate respondents de-emphasize incorporating

Table 3 The extent evidence-based clinical practice within the past month among chiropractic orthopedic diplomates ( $n=135)$

\begin{tabular}{|c|c|c|c|c|c|}
\hline & Never (\%) & 1-5 times (\%) & $6-10$ times $(\%)$ & $11-15$ times $(\%)$ & $\geq 16$ times $(\%)$ \\
\hline I have read/reviewed professional literature related to my practice & $2(1.5)$ & $64(47.4)$ & $26(19.3)$ & $12(8.9)$ & $31(23.0)$ \\
\hline $\begin{array}{l}\text { I have read/reviewed clinical research findings related } \\
\text { to my practice }\end{array}$ & $8(5.9)$ & $72(53.3)$ & $22(16.3)$ & $11(8.1)$ & $22(16.3)$ \\
\hline $\begin{array}{l}\text { I have used professional literature or research findings to assist } \\
\text { my clinical decision-making }\end{array}$ & $9(6.7)$ & $66(48.9)$ & $24(17.8)$ & $8(5.9)$ & $28(20.7)$ \\
\hline $\begin{array}{l}\text { I have used professional literature or research findings to } \\
\text { change my clinical practice }\end{array}$ & 17 (12.6) & $78(57.8)$ & $14(10.4)$ & $4(3.0)$ & $22(16.3)$ \\
\hline $\begin{array}{l}\text { I have used an online database to search for practice } \\
\text { related literature or research }\end{array}$ & 37 (27.4) & $53(39.3)$ & $19(14.1)$ & $7(5.2)$ & $19(14.1)$ \\
\hline $\begin{array}{l}\text { I have used and online search engine to search for practice } \\
\text { related literature or research }\end{array}$ & $8(5.9)$ & $48(35.6)$ & 37 (27.4) & $16(11.9)$ & $26(19.3)$ \\
\hline $\begin{array}{l}\text { I have consulted a colleague or industry expert to assist } \\
\text { my clinical decision-making }\end{array}$ & $24(17.8)$ & $77(57.0)$ & $14(10.4)$ & $6(4.4)$ & $14(10.4)$ \\
\hline $\begin{array}{l}\text { I have referred to magazines, layperson/self-help books, } \\
\text { or non-government/non-education institution websites } \\
\text { to assist my clinical decision-making }\end{array}$ & $61(45.2)$ & $51(37.8)$ & $12(8.9)$ & $4(3.0)$ & $7(5.2)$ \\
\hline
\end{tabular}


Table 4 Sources of information chiropractic orthopedic diplomates use to inform clinical decision-making ${ }^{*}(n=135)$

Average

ranking (SD)

Traditional knowledge

$3.20(2.46)$

Published clinical evidence (e.g. clinical trials)

$3.67(2.56)$

Clinical practice guidelines

$4.55(2.73)$

Textbooks

$5.01(2.55)$

Consulting fellow practitioners or experts

$5.47(2.01)$

Personal intuition

$5.56(2.60)$

Personal preference

$6.53(2.67)$

Published experimental/laboratory evidence

(e.g. animal or test tube studies)

Patient preference

$6.64(2.96)$

Trial and error

$6.98(2.31)$

$7.41(2.53)$

"Sources were ranked as most-to-least frequently used (1-10), respectively.

the patient's preference into clinical decision-making. Traditional knowledge was also reported as the most common source of information for clinical decision-making. Unfortunately, traditional knowledge was not further defined and we are uncertain how each respondent interpreted this source of information. Whether respondents assumed traditional knowledge to indicate intuitive ways of knowing or knowledge resulting from clinical experience has a substantial impact on the interpretation of this finding. Further refinement of this response identifies an area of improvement for future evaluations of the Chiropractic E-BASE questionnaire. A persistent criticism of EBCP is that it neglects aspects of clinical decisionmaking not resulting from clinical research, [15] even though the core concept of this model is to incorporate the clinical expertise, patient preference, and the best available evidence when making clinical decisions [16]. Whether DCs perceive clinical decision-making to originate from the amalgamation of clinical experience, patient preferences, and the best available research evidence is another area of improvement for future refinement of the Chiropractic E-BASE questionnaire.

It is imperative that the results of this survey be considered in the context of self-rated perceptions. It has been argued that the accuracy of self-reporting is poor [37] and result in over-estimating competence of actual EBCP performance and knowledge $[27,38,39]$. Future investigations into whether responses to the Chiropractic E-BASE questionnaire are associated with actual performance are warranted. It is also important to assess the EBCP perceptions of a broader sample of DCs.

\section{Study limitations}

This project has 3 important limitations. First, while every attempt was made to maximize the response rate, we are unable to assess the generalizability of our sample to the total population of chiropractic orthopedic diplomates. Our sample was a convenience sample of ACO members limited to those with email addresses who did not previously opt-out from SurveyMonkey ${ }^{\text {tw }}$ surveys.

Second, the pretesting phase of the Chiropractic EBASE questionnaire for this project was not a substitution for formal validation techniques. Validation of the Chiropractic E-BASE questionnaire is an important next step in this line of inquiry. Therefore, the results of this survey are descriptive and are intended to inform future development of the Chiropractic E-BASE questionnaire.

Table 5 Barriers preventing chiropractic orthopedic diplomates from practicing evidence-based clinical practice $(n=132)$

\begin{tabular}{|c|c|c|c|c|}
\hline & Not a barrier $(\%)$ & $\begin{array}{c}\text { A minor } \\
\text { barrier (\%) }\end{array}$ & $\begin{array}{c}\text { A moderate } \\
\text { barrier (\%) }\end{array}$ & $\begin{array}{c}\text { A major } \\
\text { barrier (\%) }\end{array}$ \\
\hline Lack of clinical evidence in CAM & $18(13.6)$ & $42(31.8)$ & $58(43.9)$ & $14(10.6)$ \\
\hline Lack of industry support for EBCP & $50(37.9)$ & $58(43.9)$ & $22(16.7)$ & $2(1.5)$ \\
\hline Lack of time & $18(13.6)$ & $48(36.4)$ & $43(32.6)$ & $23(17.4)$ \\
\hline Insufficient skills for locating research & $50(37.9)$ & $54(40.9)$ & $21(15.9)$ & $7(5.3)$ \\
\hline Insufficient skills for interpreting research & $45(34.1)$ & $55(41.7)$ & $24(18.2)$ & $8(6.1)$ \\
\hline Insufficient skills to critically appraise/evaluate the literature & $40(30.3)$ & $60(45.5)$ & $25(18.9)$ & $7(5.3)$ \\
\hline Insufficient skills to apply research findings to clinical practice & $44(33.3)$ & $65(49.2)$ & $20(15.2)$ & $3(2.3)$ \\
\hline Patient preference for treatment & $50(37.9)$ & $58(43.9)$ & $22(16.7)$ & $2(1.5)$ \\
\hline Lack of resources & $86(65.2)$ & $33(25.0)$ & $12(9.1)$ & $1(0.8)$ \\
\hline Lack of incentive to participate in EBCP & $48(36.4)$ & $41(31.1)$ & $29(22.0)$ & $14(10.6)$ \\
\hline Lack of interest in EBCP & $73(55.3)$ & $45(34.1)$ & $7(5.3)$ & $7(5.3)$ \\
\hline Lack of relevance to chiropractic practice & $63(47.7)$ & $47(35.6)$ & $19(14.4)$ & $3(2.3)$ \\
\hline Lack of colleague support for EBCP & $62(47.0)$ & $38(28.8)$ & $24(18.2)$ & $8(6.1)$ \\
\hline
\end{tabular}


Lastly, the number of respondents decreased as the survey progressed through each section, presumably from dropout. There were 15 respondents who failed to complete the survey, which corresponds to $10 \%$ of all respondents. Respondents who failed to complete to survey were not contacted to investigate the reason for dropout.

\section{Conclusion}

This study is a first step in investigating the perceptions, knowledge and use of EBCP within DCs. Chiropractic orthopedic diplomates perceive EBCP to be important to the practice of chiropractic and fundamental to the advancement of the profession. Access to resources was reported to facilitate the use of EBCP and an emphasis on EBCP continuing education may allow more DCs to become familiar with EBCP. Further refinement of the Chiropractic E-BASE questionnaire is needed to investigate whether clinical decision-making is informed by the combination of clinical expertise, patient preference, and best available research evidence.

\section{Abbreviations}

EBCP: Evidence-based clinical practice; ACO: Academy of Chiropractic Orthopedists; CAM: Complementary and alternative medicine; E-BASE: EvidenceBased Practice Attitudes and Utilization Survey.

\section{Competing interests}

The authors declare that they have no competing interests.

\section{Authors' contributions}

Each of the authors contributed to the conception and methods development of this project. CBR carried out the adaptation of the Chiropractic E-BASE questionnaire, created the online survey format, administered the pretesting, sent survey requests to the ACO membership, and drafted the initial manuscript. CRL, RDV, and DJL provided substantive intellectual contributions and assisted in revising the manuscript into final form. All authors approved the final manuscript.

\section{Authors' information}

CBR is an Instructor within the Life Sciences Department at Palmer College of Chiropractic, Davenport, IA.

CRL is a Professor and Director of Research at Palmer College of Chiropractic, Davenport IA.

RDV is an Assistant Professor at the Palmer Center for Chiropractic Research, Palmer College of Chiropractic, Davenport, IA.

DJL is the Senior Director for the Center for Teaching and learning at Palmer College of Chiropractic, Davenport, IA.

\section{Acknowledgements}

We would like to thank Dr. Matthew J. Leach for permitting the adaptation of the original E-BASE questionnaire for use with the chiropractic profession. We would also like to thank the Executive Board of the Academy of Chiropractic Orthopedists' for providing contact information to their membership directory.

This research project was conducted in a facility constructed with support from Research Facilities Improvement Program Grant Number C06 RR15433-01 from the National Center for Research Resources, National Institutes of health. Also, a Graduate Research Assistantship sponsored by the Palmer Center for Chiropractic Research facilitated the conception, analysis, and drafting of this research project.

\section{Author details}

${ }^{1}$ Palmer College of Chiropractic, 1000 Brady Street, Davenport, IA 52803, USA. ${ }^{2}$ Palmer Center for Chiropractic Research, 741 Brady Street, Davenport, IA 52803, USA.

Received: 8 August 2013 Accepted: 29 September 2013 Published: 6 December 2013

\section{References}

1. Sackett DL, Rosenberg WM, Gray JA, Haynes RB, Richardson WS: Evidence based medicine: what it is and what it isn't. BMJ 1996, 312:71-72.

2. Haynes RB, Devereaux PJ, Guyatt GH: Physicians' and patients' choices in evidence based practice. BMJ 2002, 324:1350

3. Leach MJ: Evidence-based practice: a framework for clinical practice and research design. Int J Nurs Pract 2006, 12:248-251.

4. Romyn DM, Allen MN, Boschma G, Duncan SM, Edgecombe N, Jensen LA, Ross-Kerr JC, Marck P, Salsali M, Tourangeau AE, et al: The notion of evidence in evidence-based practice by the nursing philosophy working group. J Prof Nurs 2003, 19:184-188.

5. Trinder L: A critical appraisal of evidence-based practice. In Evidence-based practice: a critical appriasal. Edited by Trinder L, Reynolds S. Oxford: Blackwell Science; 2000:212-241.

6. Guyatt G, Cairns J, Churchill D, Cook D, Haynes B, Hirsh J, Irvine J: Evidencebased medicine. A new approach to teaching the practice of medicine. JAMA 1992, 268:2420-2425.

7. Hatala R, Keitz SA, Wilson MC, Guyatt G: Beyond journal clubs. Moving toward an integrated evidence-based medicine curriculum. J Gen Intern Med 2006, 21:538-541.

8. Kahn K, Ryan G, Beckett M, Taylor S, Berrebi C, Cho M, Quiter E, Fremont A, Pincus $\mathrm{H}$ : Bridging the gap between basic science and clinical practice: a role for community clinicians. Implement Sci 2011, 6:34.

9. Dawes M, Summerskill W, Glasziou P, Cartabellotta A, Martin J, Hopayian K, Porzsolt F, Burls A, Osborne J: Sicily statement on evidence-based practice. BMC Med Educ 2005, 5:1

10. Bolton JE: The evidence in evidence-based practice: what counts and what doesn't count? J Manipulative Physiol Ther 2001, 24:362-366.

11. Hadley JA, Wall D, Khan KS: Learning needs analysis to guide teaching evidence-based medicine: knowledge and beliefs amongst trainees from various specialities. BMC Med Educ 2007, 7:11.

12. Forrest $\lrcorner$, Miller SA: Integrating evidence-based decision making into allied health curricula. J Allied Health 2001, 30:215-222.

13. Chipchase LS, Williams MT, Robertson VJ: Factors affecting curriculum content and the integration of evidence-based practice in entry-level physiotherapy programs. J Allied Health 2007, 36:17-23.

14. Caldwell K, Coleman K, Copp G, Bell L, Ghazi F: Preparing for professional practice: how well does professional training equip health and social care practitioners to engage in evidence-based practice? Nurse Educ Today 2007, 27:518-528.

15. Dijkers MP, Murphy SL, Krellman J: Evidence-based practice for rehabilitation professionals: concepts and controversies. Arch Phys Med Rehabil 2012, 93:S164-S176.

16. Reilly BM: The essence of EBM. BMJ 2004, 329:991-992.

17. Triano JJ, Goertz C, Weeks J, Murphy DR, Kranz KC, McClelland GC, Kopansky-Giles D, Morgan W, Nelson CF: Chiropractic in North America: toward a strategic plan for professional renewal-outcomes from the, 2006 Chiropractic Strategic Planning Conference. J Manipulative Physiol Ther 2010, 33:395-405.

18. Delaney PM, Fernandez CE: Toward an evidence-based model for chiropractic education and practice. J Manipulative Physiol Ther 1999, 22:114-118.

19. Lefebvre RP, Peterson DH, Haas M, Gillette RG, Novak CW, Tapper J, Muench JP: Training the evidence-based practitioner: university of Western States document on standards and competencies. J Chiropr Educ 2011, 25:30-37.

20. Keating J: Philosophy in Chiropractic. In Principles and Practice of Chiropractic. 3rd edition. Edited by Haldeman S. New York, NY: The McGrawHill Companies, Inc; 2005:89-91.

21. Keating JC Jr, Green BN, Johnson CD: "Research" and "science" in the first half of the chiropractic century. J Manipulative Physiol Ther 1995, 18:357-378.

22. Nelson CF, Lawrence DJ, Triano JJ, Bronfort G, Perle SM, Metz RD, Hegetschweiler K, LaBrot T: Chiropractic as spine care: a model for the profession. Chiropr Osteopat 2005, 13:9. 
23. Leach R: Evidence-based chiropractic: critical thinking in the privatepractice setting. J Am Chiropr Assoc 2005, 42:37-46.

24. The Council on Chiropractic Education: Accredidation Standards (accessed 07/02/2013). http://cce-usa.org/uploads/2013_CCE_ACCREDITATION_ STANDARDS.pdf. 1-1-2013.

25. Lawrence DJ, Polipnick J, Colby E: Barriers to and opportunities for the implementation of best practice recommendations in chiropractic: report of a focus group. J Allied Health 2008, 37:82-89.

26. Leach MJ, Gillham D: Are complementary medicine practitioners implementing evidence based practice? Complement Ther Med 2011 19:128-136.

27. Buscaglia J, Nagula S, Yuan J, Bucobo JC, Kumar A, Forsmark CE, Draganov $\mathrm{PV}$ : The practice of evidence-based medicine (EBM) in gastroenterology: discrepancies between EBM familiarity and EBM competency. Therap Adv Gastroenterol 2011, 4:283-294.

28. Sur RL, Scales CD Jr, Preminger GM, Dahm P: Evidence-based medicine: a survey of American urological association members. J Urol 2006, 176:1127-1134.

29. McColl A, Smith H, White P, Field J: General practitioner's perceptions of the route to evidence based medicine: a questionnaire survey. BMJ 1998, 316:361-365.

30. Oliveri RS, Gluud C, Wille-Jorgensen PA: Hospital doctors' self-rated skills in and use of evidence-based medicine - a questionnaire survey. J Eval Clin Pract 2004, 10:219-226.

31. Poolman RW, Sierevelt IN, Farrokhyar F, Mazel JA, Blankevoort L, Bhandari M: Perceptions and competence in evidence-based medicine: Are surgeons getting better? A questionnaire survey of members of the Dutch orthopaedic association. J Bone Joint Surg Am 2007, 89:206-215.

32. Jette DU, Bacon K, Batty C, Carlson M, Ferland A, Hemingway RD, Hill JC, Ogilvie L, Volk D: Evidence-based practice: beliefs, attitudes, knowledge, and behaviors of physical therapists. Phys Ther 2003, 83:786-805.

33. Dahm P, Poolman RW, Bhandari M, Fesperman SF, Baum J, Kosiak B, Carrick $\mathrm{T}$, Preminger GM: Perceptions and competence in evidence-based medicine: a survey of the American urological association membership. J Urol 2009, 181:767-777.

34. Stapleton AM, Cuncins-Hearn A, Pinnock C: Attitudes to evidence-based practice in urology: results of a survey. ANZ J Surg 2001, 71:297-300.

35. Wentz DS, Green BN: The evolution of chiropractic orthopedists: a bootstrapping of clinical skills. Chiropr Hist 1995, 15:92-99.

36. Leach MJ, Gillham D: Evaluation of the evidence-based practice attitude and utilization SurvEy for complementary and alternative medicine practitioners. J Eval Clin Pract 2008, 14:792-798.

37. Ward M, Gruppen L, Regehr G: Measuring self-assessment: current state of the art. Adv Health Sci Educ Theory Pract 2002, 7:63-80.

38. Young JM, Glasziou P, Ward JE: General practitioners' self ratings of skills in evidence based medicine: validation study. BMJ 2002, 324:950-951.

39. Caspi O, McKnight P, Kruse L, Cunningham V, Figueredo AJ, Sechrest L: Evidence-based medicine: discrepancy between perceived competence and actual performance among graduating medical students. Med Teach 2006, 28:318-325.

doi:10.1186/2045-709X-21-43

Cite this article as: Roecker et al: Attitudes toward evidence-based clinical practice among doctors of chiropractic with diplomate-leve training in orthopedics. Chiropractic \& Manual Therapies 2013 21:43.

\section{Submit your next manuscript to BioMed Central and take full advantage of:}

- Convenient online submission

- Thorough peer review

- No space constraints or color figure charges

- Immediate publication on acceptance

- Inclusion in PubMed, CAS, Scopus and Google Scholar

- Research which is freely available for redistribution

Submit your manuscript at www.biomedcentral.com/submit
C Biomed Central 